\title{
Overaccumulation of p53-mediated autophagy protects against betulinic acid-induced apoptotic cell death in colorectal cancer cells
}

\author{
Sen Wang ${ }^{1,2}$, Kexin Wang ${ }^{3}$, Chundong Zhang ${ }^{1,2}$, Wanfeng Zhang ${ }^{4}$, Qian Xü ${ }^{5}$, Yitao Wang ${ }^{1,2}$, Yulin Zhang ${ }^{6}$, Yi Li ${ }^{1,2}$, Ying Zhang ${ }^{1,2}$, \\ Huifang Zhu ${ }^{1,2}$, Fangzhou Song ${ }^{1,2}$, Yunlong Lei ${ }^{*, 1,2}$ and Youquan Bu ${ }^{*, 1,2}$
}

Betulinic acid (BA) exhibits cytotoxic activity against some cancer cells. However, the molecular mechanism of BA against CRC cells was little reported. Here, we proved that BA elicited CRC cells' growth inhibition and apoptosis in a dose-dependent manner. In addition, BA treatment induced autophagy via inhibiting the AKT-MTOR signaling pathway. Inhibition of autophagy by either administration of autophagic inhibitor chloroquine or siRNA-mediated knockdown of ATG5 could augment BA-induced apoptotic cell death as well as inhibition of cell proliferation. Moreover, we found that p53 was firstly activated by short exposure to BA and then was rapidly degraded via the ubiquitin-mediated degradation pathway in both wtp53 and mutp53 CRC cells. Notably, more preferential cytotoxicity of BA was obtained in mutp53 cells (IC50 values: HT29, $125 \mu \mathrm{M}$; SW480, $58 \mu \mathrm{M}$ ) rather than wtp53 cells (IC50 values: HCT116, $178 \mu \mathrm{M}$ ). Further experiments demonstrated that siRNA-mediated p53 knockdown attenuated BA-induced autophagy, and forced overexpression of p53 augmented BA-induced autophagy, indicating that p53-enhanced BA-induced autophagy. Moreover, BA enhanced the sensitivity of mutp53 cells to chemotherapy drugs such as 5-FU and ADR by degradation of mutp53. Overall, our study proved that BA could induce CRC cell death by inducing apoptosis and reduce the overaccumulation of BA-induced protective autophagy by degrading wtp53 and mutp53 dependent on the ubiquitin-mediated degradation pathway to achieve killer effect, suggesting that BA might serve as a novel desirable drug for mutp53 cancer therapy.

Cell Death and Disease (2017) 8, e3087; doi:10.1038/cddis.2017.485; published online 5 October 2017

Colorectal cancer is the third most common cancer and the fourth most common cause of cancer death worldwide. ${ }^{1,2}$ As alternative treatments, new chemotherapy agents using novel mechanisms to induce CRC cell death are needed, whereas plants are an important source for potential anticancer compounds. $^{3-5}$ Betulinic acid (BA), a naturally occurring pentacyclic triterpene, has shown anticancer property in several human cancers ${ }^{6-15}$ and no effect on untransformed cells. ${ }^{16-18}$ However, the mechanism of BA-induced antitumor effect has been still on debate. ${ }^{12,19}$ In CRC cells, BA could induce apoptosis through the mitochondrial pathway, ${ }^{20}$ inhibited cell growth of CRC cells by downregulating Sp transcription factors in SW480 and RKO cells, ${ }^{21}$ or by suppressing NF- $k$ B and STAT3 signaling in HT29 cells. ${ }^{22}$ It has also been reported that $\mathrm{BA}$ can function as NF- $\mathrm{B}$ activator in a number of other cancer cell lines, ${ }^{23}$ suggesting that the antitumor mechanisms of BA was dependent on tumor type.

Autophagy is a catabolic process that allows cellular macromolecules to be broken down and recycled as metabolic precursors. ${ }^{24}$ Autophagy is usually activated in cancer cells challenged with various stresses. ${ }^{25-29}$ In response to chemotherapy stress, autophagy probably has four different functions including cytoprotective, cytotoxic, non-protective and cytostatic form. ${ }^{30-35}$ BA could induce autophagy in multiple myeloma cells and glioblastoma cells, ${ }^{36}$ whereas autophagic flux inhibition promoted apoptosis in human multiple myeloma KM3 cells. Furthermore, BA or BA analog could induce autophagy in HeLa, A549, MCF7, SW480 and HT29 cells, and autophagic salvage counterbalanced BA-induced cell death in HeLa cells. ${ }^{10,37}$ Although studies observed that BA could induce autophagy, the role of autophagy as a cell death mechanism was not minutely addressed for BA-treated CRC cells.

The tumor suppressor $\mathrm{p} 53$ is implicated in a wide range of cellular processes, such as cell-cycle arrest and apoptosis. ${ }^{38-40}$ p53 binds specifically to DNA and regulates transcription of target genes, such as $P 21, B I M, B A X, P U M A$ and NOXA, to trigger cell death. ${ }^{41}$ However, mutp53 in a large fraction of human cancers could promote evasion of apoptosis, accelerate tumor progression and chemoresistance, which is defined as mutp53 gain-of-function (GOF). ${ }^{40,42-45}$ Pharmacological inactivation of mutp53 and effective therapy that targets mutp53 degradation have emerged as a promising strategy to improve cancer therapy.40,44,46 In addition, p53 can either be a positive or a negative regulator of autophagy. ${ }^{4,48}$ At basal levels, p53 is recognized as an inhibitor of autophagy through protein-protein interactions in mitochondria. ${ }^{49,50}$ In response to stress, p53 translocated to

\footnotetext{
${ }^{1}$ Department of Biochemistry and Molecular Biology, Chongqing Medical University, Chongqing 400016, China; ${ }^{2}$ Molecular Medicine and Cancer Research Center, Chongqing Medical University, Chongqing 400016, China; ${ }^{3}$ Department of Radiology, Affiliated Hospital, Southwest Medical University, Luzhou, Sichuan 646000, China; ${ }^{4}$ Department of Bioinformatics, Chongqing Medical University, Chongqing 400016, China; ${ }^{5}$ Department of Anesthesiology, North Sichuan Medical College, Nanchong, Sichuan 637000, China and ${ }^{6}$ Department of Basic medicine, Chongqing Medical University, Chongqing, 400016, China

${ }^{*}$ Corresponding author: Y Bu or Y Lei, Department of Biochemistry and Molecular Biology, Molecular Medicine and Cancer Research Center, Chongqing Medical University, Yixueyuan Road, Yuzhong District, Chongqing 400016, China. Tel: +86 2368485991 or +86 23 13648323625; E-mail: buyqcn@aliyun.com or leiyunlong@126.com Received 28.5.17; revised 22.8.17; accepted 24.8.17; Edited by A Stephanou
} 
the nucleus and promoted autophagy by trans-activating its target genes. ${ }^{51,52}$ BA triggered an apoptosis pathway different from standard chemotherapeutic drugs because BA-induced apoptosis was independent of p53 in neuroectodermal cancer cells, ${ }^{53}$ melanoma cells and glioblastoma cells. ${ }^{54}$ However, no research was reported regarding whether BA induced CRC cell death independent of p53 status and histotype, and the related detailed mechanism remains unknown.

In this study, we found that BA induced a pro-survival effect of autophagy in CRC cells and p53 can further augment this autophagy. To avoid the overaccumulation of protective autophagy, BA would induce both wtp53 and mutp53 degradation, which makes BA exhibiting preferential cytotoxicity to mutp53 cells.

\section{Results}

BA inhibits cell proliferation and induces apoptosis in CRC cells. To determine the anticancer effect of BA in CRC cells, HCT116, SW480 and HT29 cells were treated with different concentrations of BA, and then cell proliferation was assayed with a CCK8 regent kit. We found that administration of BA dose-dependently decreased the proliferation of all three CRC cells. IC50 values of BA against CRC cells were $178 \mu \mathrm{M}$ (HCT116), $58 \mu \mathrm{M}$ (SW480) and $125 \mu \mathrm{M}$ (HT29; Figure 1a). Chemotherapeutic drug-induced cell proliferation inhibition was mainly because of the initiation of apoptosis. ${ }^{55}$ Annexin-V/PI double staining and DAPI staining were used to estimate the effect of BA on apoptosis in CRC cells. The results showed that $B A$ induced apoptosis in a dosedependent manner (Figures $1 \mathrm{~b}$ and $\mathrm{c}$ ). Finally, we further detected the activation of PARP, which is a key factor of apoptosis. ${ }^{45}$ Results showed that BA induced PARP cleavage in a dose-dependent manner (Figure 1d), indicating that BA induced CRC cells' apoptosis. In addition, p53 protein was decreased and its target gene $B A X$ was unchanged after BA treatment (Figure 1d), suggesting that p53 may be involved in BA-induced $\mathrm{CRC}$ cell death in a special manner.

BA initiates autophagy in CRC cells. Autophagy has an important role in the drug treatment of cancers. ${ }^{56}$ To investigate whether BA could initiate autophagy in CRC cells, transmission electron microscopy (TEM) was used to monitor autophagy. ${ }^{24}$ The formation of double-membraned autophagic vacuoles was frequently observed in CRC cells treated with BA, but not in control cells (Figure 2a). In addition, we tested the formation of acidic vesicular organelle (AVOs), another major feature of autophagy ${ }^{57}$ in three kinds of CRC cells. Results showed that the numbers of AVOs notably dose-dependently increased in these CRC cells (Figure 2b).

To further confirm whether BA initiates autophagy in CRC cells, the processing of LC3-I to its PE-conjugated LC3-II was measured by immunoblotting. As shown in Figure 2c, BA increased the conversion of LC3-I to LC3-II in a dosedependent manner, which was further supported by the a
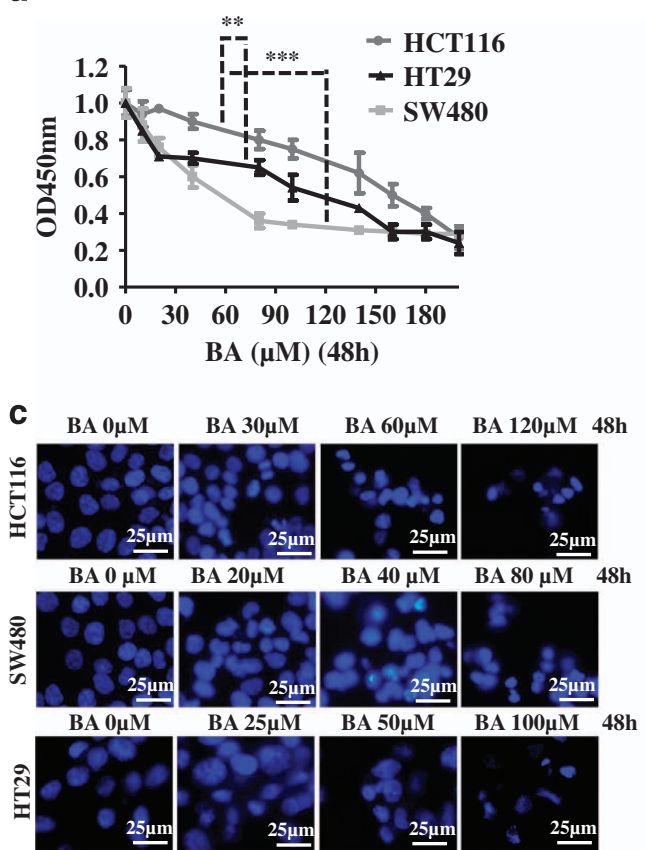
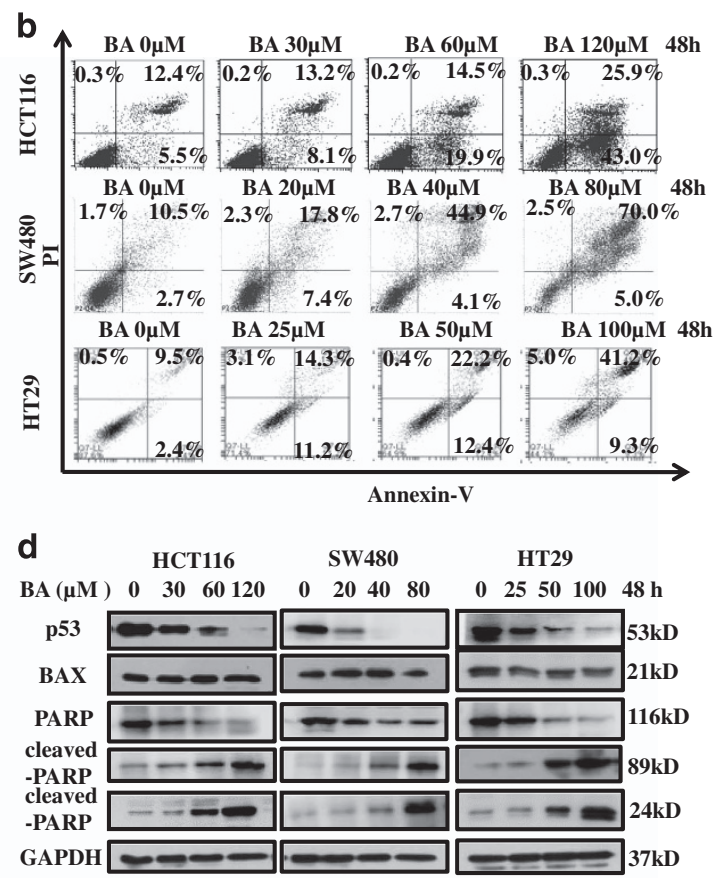

Figure 1 BA inhibits CRC cell proliferation and induces apoptosis. (a) Three kinds of CRC cells were seeded into 96-well plates and were treated with the indicated concentrations of BA for $48 \mathrm{~h}$. Cell proliferation assay was performed by CCK8 kit. Data are shown as means \pm S.D. $(n=6)$. Comparisons of IC50 were performed by repeated measures ANOVA and Bonferroni's test using GraphPad Prism software. ${ }^{* \star} P<0.01$; ${ }^{* \star \star} P<0.0001$. (b) Three kinds of CRC cells were treated with BA for $48 \mathrm{~h}$ at indicated concentrations, and apoptosis rates were analyzed by AV/PI double-staining flow cytometry. (c) Three kinds of CRC cells were seeded into 24-well plates and were treated with BA at indicated concentrations for $48 \mathrm{~h}$, and then morphology of the nucleus was observed with the DAPI staining method. (d) Three kinds of CRC cells were treated with BA at indicated concentrations for $48 \mathrm{~h}$, and then the apoptosis-related protein was analyzed by immunoblotting. GAPDH was used as the internal control. DMSO was the control group 
a

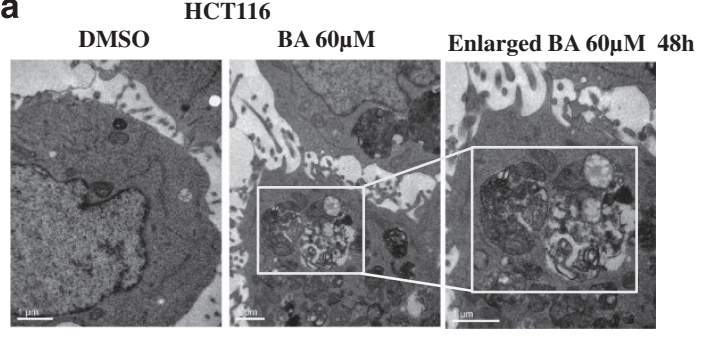

b

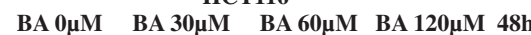

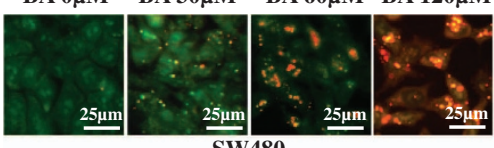

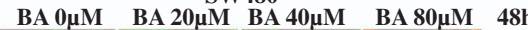

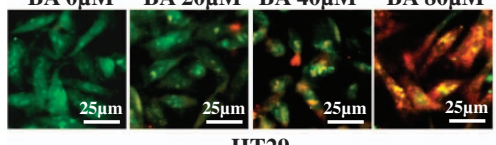

HT29

BA $0 \mu \mathrm{M} \quad$ BA $25 \mu \mathrm{M} \quad$ BA $50 \mu \mathrm{M} \quad$ BA $100 \mu \mathrm{M} \quad 48 \mathrm{~h}$

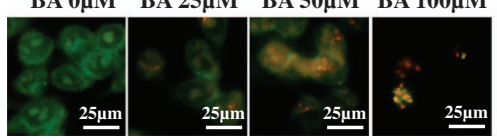

C

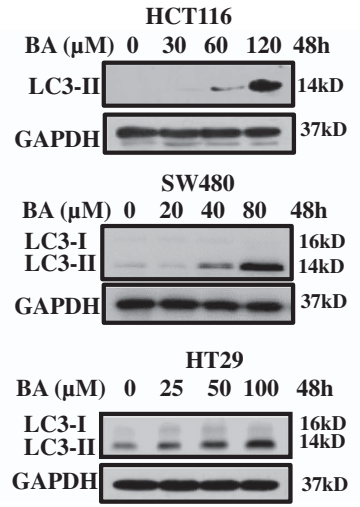

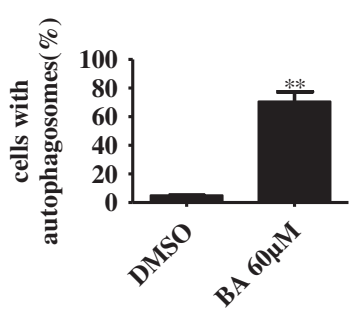

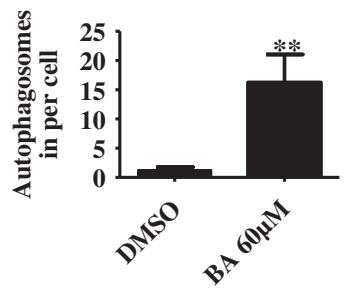

d

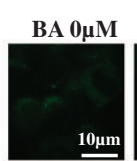

HCT116
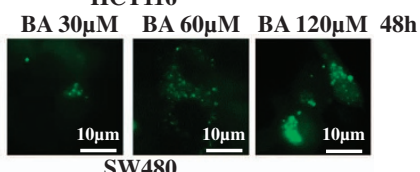

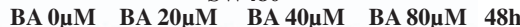
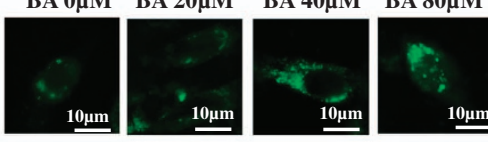

ВА $0 \mu \mathrm{M} \quad$ ВА $25 \mu \mathrm{M}$ ВА $50 \mu \mathrm{M} \quad$ ВА $100 \mu \mathrm{M} 48 \mathrm{~h}$

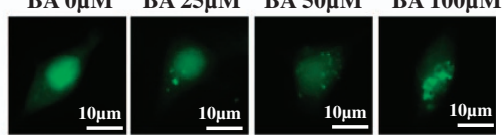

Figure 2 BA induces formation of autophagic vacuoles and AVOs in CRC cells. (a) Left: HCT116 cells were treated with BA at $60 \mu \mathrm{M}$ for $48 \mathrm{~h}$, and then autophagic vacuoles were observed under TEM. DMSO was the control group. Autophagic vacuoles in cells were boxed by the white rectangle and enlarged in the indicated picture. Right: statistical analysis of observation of autophagic vacuoles was described in left. ${ }^{* \star} P<0.01$. (b) HCT116, SW480 and HT29 cells were treated with BA at indicated concentrations for $48 \mathrm{~h}$, and then acidic autophagic vacuoles were detected by acridine orange staining method. DMSO was the control group. (c) HCT116, SW480 and HT29 cells were treated with BA at indicated concentrations for $48 \mathrm{~h}$. Whole-cell lysates were extracted and LC3 protein was detected by immunoblotting. GAPDH was used as internal control. (d) HCT116, SW480 and HT29 cells were seeded on the slides in 24-well plates, transfected with GFP-LC3 for $48 \mathrm{~h}$ next day and then treated with BA at indicated concentrations for another $48 \mathrm{~h}$. GFP-LC3 puncta was observed under high-magnification fluorescence microscopy

results that BA treatment increased LC3 punctuates in the cells containing GFP-LC3 plasmids (Figure $2 \mathrm{~d}$ and Supplementary Figure S1). The distribution of endogenous LC3 in CRC cells was also analyzed by indirect immunofluorescence staining. As shown in Supplementary Figure S2A, more specific LC3 punctuates were found in BA-treated cells compared with the control group. Finally, qRT-PCR was performed to determine the mRNA expression levels of BECLIN1, ATG7, ATG12 and ATG5, which are involved in the formation of autophagosome. ${ }^{58,59}$ Results showed that BA induced the expression of autophagy-related genes in a dosedependent manner (Supplementary Figure S2B). These results demonstrated that $B A$ could induce autophagy in CRC cells.

BA increases the autophagy flux in CRC cells. To determine that BA could also induce autophagy flux in CRC cells, the colocalization of LC3 and LAMP1 was firstly analyzed by indirect immunofluorescence assay, which is often used as a marker for autophagy flux. ${ }^{7}$ The results showed that the colocalization of LC3 and LAMP1 was increased in BA-treated CRC cells compared with the control group (Figure 3a). Another commonly used method for measurement of the autophagy flux is to monitor the conversion of LC3-I to LC3-II in the presence of lysosome inhibitor. ${ }^{58}$ We found that BA co-treatment with E-64 day/ pepstain $A$ or chloroquine led to further accumulation of
LC3-II in CRC cells (Figure 3b), indicating that BA promoted the autophagy flux in CRC cells. However, interestingly, the mRNA and protein expression of SQSTM1, another marker of the autophagy flux, which is efficiently degraded in the process of autophagy, ${ }^{60,61}$ were notably increased dosedependently in the BA treatment group compared with the control group, and SQSTM1 knockdown in HCT116 cells hadn't an obvious influence on BA induced the conversion of LC3-I to LC3-II (Supplementary Figure S3), suggesting that BA-induced autophagy was involved in accumulation of SQSTM1, whereas SQSTM1 did not affect BA-induced autophagy.

Blockage of autophagy enhances BA-induced proliferation inhibition and apoptosis in CRC cells. To determine the role of autophagy on BA-induced antitumor effect in CRC cells, we inhibited autophagy by autophagy key gene silencing method or administration of autophagy inhibitors. Results showed gene silencing of autophagy key gene ATG5 or administration of autophagy inhibitors chloroquine notably enhanced BA-induced proliferation inhibition and apoptosis in CRC cells (Figure 4 and Supplementary Figures S4 and S5). Consistently, the cleavage of pro-apoptosis protein PARP was also enhanced in ATG5 silencing or CQ treatment in contrast to the control (Supplementary Figure S5). Besides that, another autophagy key gene BECLIN1 silencing and cotreatment with another autophagy inhibitor 3-MA, an inhibitor 
a

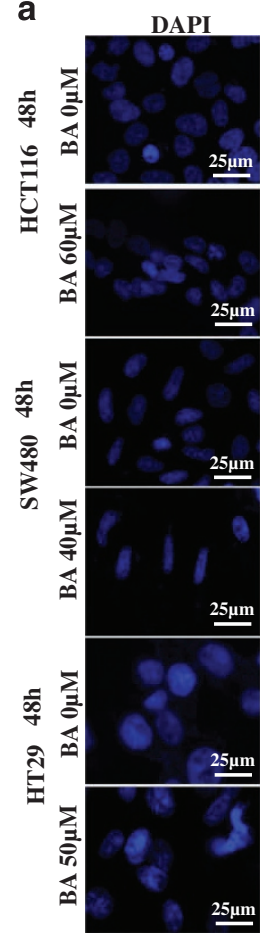

LAMP1
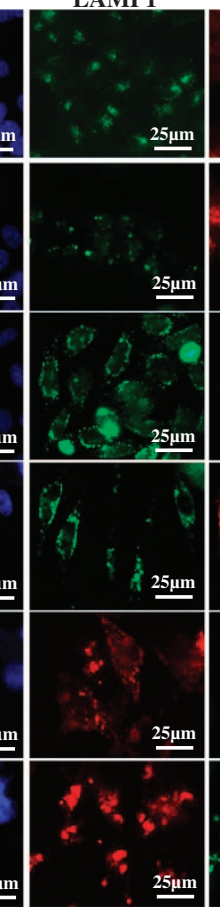

LC3
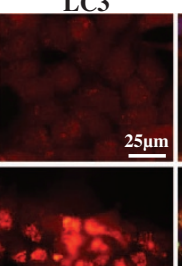

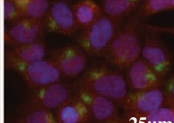

b

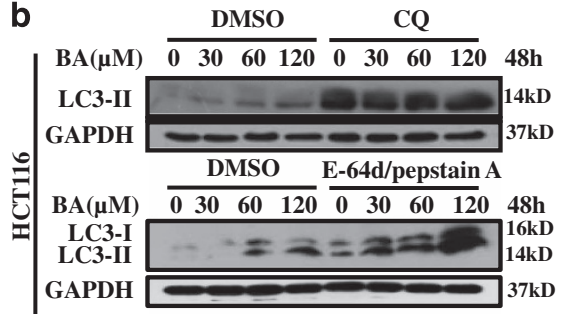

DMSO CQ

$\begin{array}{lllllllllllll}\mathrm{BA}(\mu \mathrm{M}) & 0 & 20 & 40 & 80 & 0 & 20 & 40 & 80 & 48 \mathrm{~h}\end{array}$
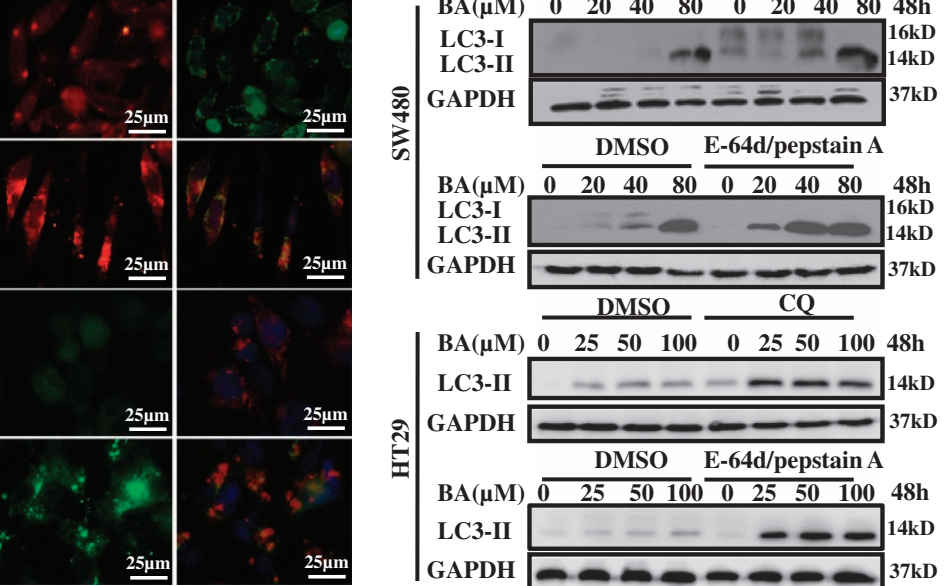

赵

DMSO E-64d/pepstain A

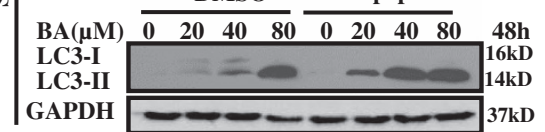

DMSO

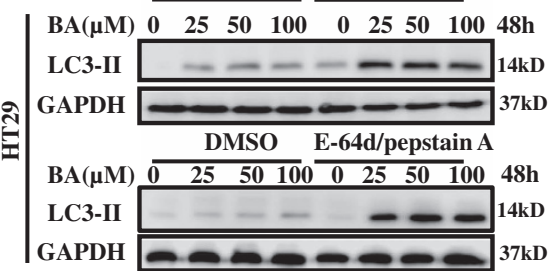

Figure 3 BA induces autophagy flux in CRC cells. (a) HCT116, SW480 and HT29 were seeded on slides in 24-well plates and were treated with indicated concentrations of BA for $48 \mathrm{~h}$. Finally, co-location of LAMP1 and LC3 was determined by indirect immunofluorescence. Nucleus was stained with DAPI. LC3 and LAMP1 puncta were observed by high-magnification fluorescence microscopy. (b) HCT116, SW480 and HT29 were treated with indicated concentrations of BA for $48 \mathrm{~h}$ in the absence or presence of chloroquine $(20 \mu \mathrm{M})$ or E-64D/Pepstain A (each at $10 \mu \mathrm{g} / \mathrm{ml})$. LC3 were detected by immunoblotting. GAPDH was used as an internal control. CQ, chloroquine. DMSO was the control group

blocking the initial step of autophagy, ${ }^{62}$ also successfully inhibited BA-induced conversion of LC3-I to LC3-II and promoted BA-induced cleavage of pro-apoptosis protein PARP (Supplementary Figure S5). Taken together, these results demonstrate that autophagy has a protective role in BA-treated CRC cells.

The AKT-MTOR signaling pathway was involved in BAinduced autophagy. The AKT-MTOR signaling is reviewed as a key negative regulator of autophagy. ${ }^{63}$ Therefore, we verified whether BA-induced autophagy is also the case in CRC cells. As shown in Figure 5a, BA treatment inhibited phosphorylation of both AKT (S473) and MTOR (S2448) in HCT116, SW480 and HT29 cells. In addition, overexpression of continuous activation Myr-AKT-delta vector decreased BAinduced conversion of LC3 contrast with control in three kinds of CRC cells (Figure $5 \mathrm{~b}$ ), suggesting that BA could induce autophagy by inhibiting AKT-MTOR signaling in CRC cells.

BA first activated and then rapidly degraded p53 by the ubiquitin-proteasome pathway in mutp53 and wtp53 harboring CRC cells. To analyze why and how BA affects p53 expression, three kinds of CRC cells harboring either mutant p53 (SW480 and HT29) or wild-type p53 (HCT116) were analyzed by immunoblotting. As shown in Figure 1d, BA strongly reduced the levels of mutp53 and wtp53 protein, but increased their mRNA levels and the mRNA expression of wild-type p53-targeted genes (such as NOXA, PUMA, P21 and $B A X$; Figure $6 a)$, suggesting that BA can enhance p53 degradation. To investigate the mechanisms of BA-induced p53 degradation, we next performed cycloheximide chase experiment. As shown in Figure 6b, BA markedly decreased the half-life of both wtp53 and mutp53 proteins. However, proteasome inhibition by MG132 rescued BA-induced degradation of wtp53 and mutp53 (Figure 6c). In addition, autophagy inhibition did not affect BA-induced p53 protein degradation and MDM2 protein was also decreased by BA (Supplementary Figures $\mathrm{S} 5 \mathrm{~A}$ and $\mathrm{B}$ ), indicating that BAinduced p53 protein degradation is not dependent on autophagy regulation and its negative regulator, the E3 ubiquitin ligase MDM2. Taken together, our results indicated that BA degraded both wild-type p53 and mutant p53 protein by ubiquitin-proteasome pathway independent of MDM2. Owing to that BA can induce transcription of p53 and activation of p53 target gene, p53 may be activated and involved in regulating $\mathrm{CRC}$ apoptosis in the early stage of $\mathrm{BA}$ treatment. To this end, we examined a short kinetic of p53 quantity after BA treatment for $0,4,8,12,24$ and $48 \mathrm{~h}$. Results showed that BA induced p53 expression and activation till $12 \mathrm{~h}$ in HCT116 and HT29 cells and till $4 \mathrm{~h}$ in SW480 cells, and then rapidly degraded p53 in three CRC cells (Figure 6d; Etoposide was used as a positive control to activate p53 in CRC cells (Supplementary Figure S6)), suggesting that short exposure to BA firstly activates p53 and then rapidly degrades $p 53$ by the ubiquitin-proteasome pathway. 


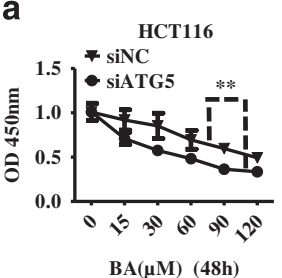

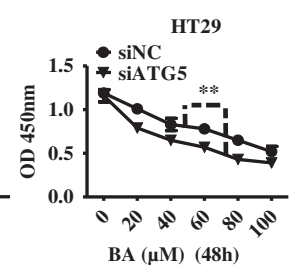

siATG5

C

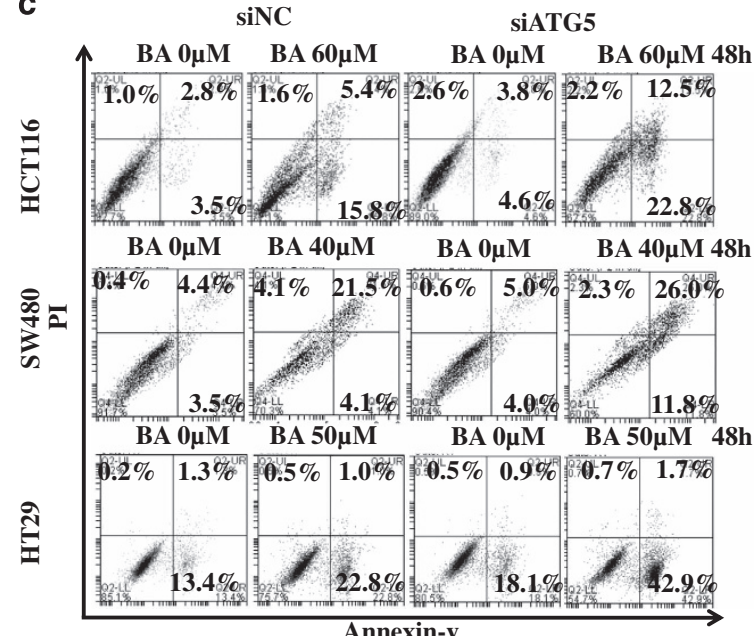

b
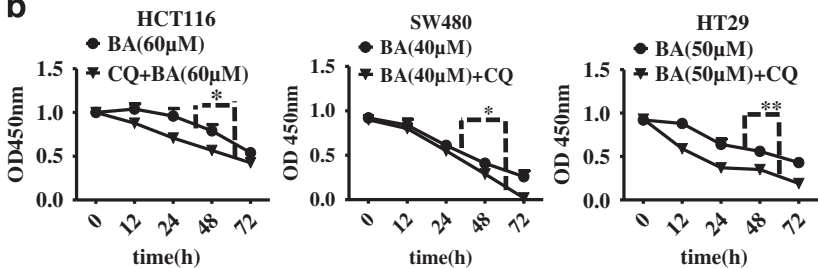

d

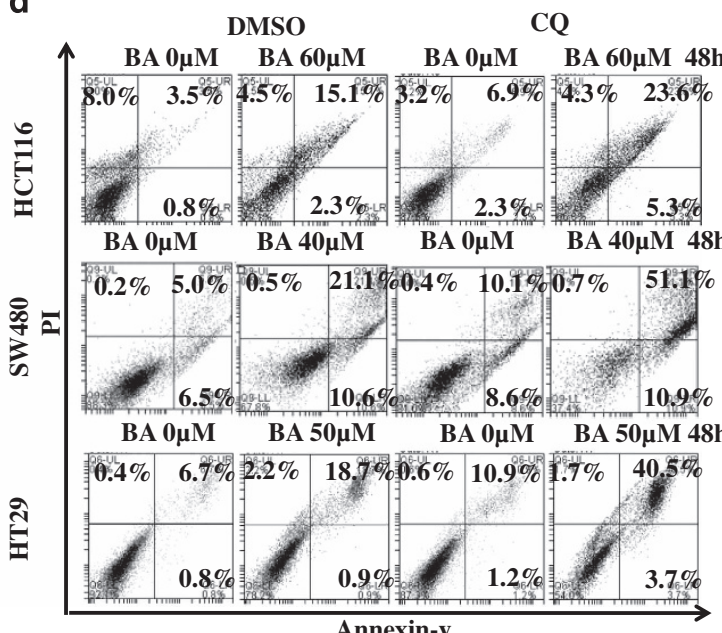

Figure 4 Inhibition of autophagy enhances BA-induced proliferation inhibition and apoptosis in CRC cells. (a) Small interference RNA specific to ATG5 and negative control were transfected in HCT116, SW480 and HT29 cells for $24 \mathrm{~h}$ and then treated with BA at indicated concentrations for another $48 \mathrm{~h}$. Cell viability was assessed by CCK8 kit. (b) HCT116, SW480 and HT29 cells were treated with BA in the presence or absence of CQ $(20 \mu \mathrm{M})$ for $48 \mathrm{~h}$. Cell viability was analyzed by CCK8 kit. Data are means \pm S.D. ( $n=5$ or 6 , Student's $t$-test). ${ }^{*} P<0.05$, ${ }^{*} P<0.01$. (c) Small interference ATG5 and negative control were transfected in HCT116, SW480 and HT29 cells for $24 \mathrm{~h}$ and then treated with the indicated BA for $48 \mathrm{~h}$. Cell apoptosis rates were detected by AV/PI double-staining flow cytometry. DMSO was the control group. (d) HCT116, SW480 and HT29 cells were treated with $\mathrm{BA}$ at indicated concentrations in the presence or absence of $\mathrm{CQ}(20 \mu \mathrm{M})$ for $48 \mathrm{~h}$. Cell apoptosis rates were detected by AV/PI double-staining flow cytometry. DMSO was the control group

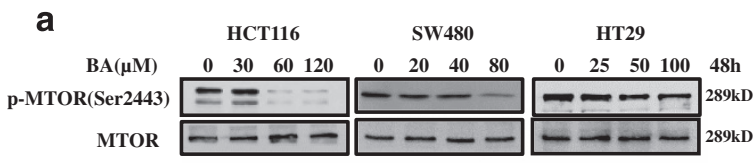

$\begin{array}{lllllllllllll}\text { P-MTOR(Ser2443)/MTOR } & 1.2 & 1.3 & 0.2 & 0.1 & 1.5 & 1.0 & 1.1 & 0.6 & 1.5 & 1.3 & 0.9 & 0.8\end{array}$
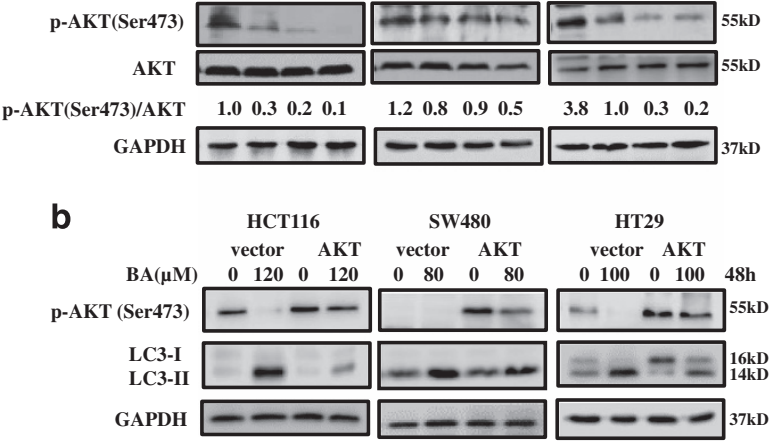

Figure 5 BA induces autophagy by inhibiting the AKT-MTOR signaling pathway. (a) HCT116, SW480 and HT29 cells were treated with indicated concentration of BA for $48 \mathrm{~h}$, and then total MTOR, total AKT, phosphorylation of MTOR (P-MTOR) and phosphorylation of AKT (P-AKT) were analyzed by immunoblotting. The ratios of P-MTOR/MTOR and P-AKT/AKT were calculated with Image J. (b) Myr-AKT-delta vectors and control DNA were transfected into HCT116, SW480 and HT29 cells for $48 \mathrm{~h}$, and then the transfected cells were treated with indicated concentrations of $\mathrm{BA}$ for $48 \mathrm{~h}$. P-AKT and LC3 were detected by immunoblotting. GAPDH was used as an internal control. DMSO was the control group
Finally, we measured the influence of p53 on BA-induced apoptosis by gain and lose of p53 or mutp53. Interestingly, knockout of p53 unexpectedly restrained BA-induced proliferation inhibition and apoptosis in HCT116 cells (Figures 7a, b and 8a, middle), suggesting that early stage of BA-induced $p 53$ may have effects on apoptosis in HCT116 cells. In addition, mutp53-R273H or mutp53-R175H (another important hotspot mutation that usually occurred in cancer ${ }^{43}$ ) overexpression decreased BAinduced proliferation inhibition and apoptosis in HCT116 p53 - / cells (Figures 7c and d; Supplementary Figure S7A; Figure 8a, right ), whereas p53 silencing augmented $B A$-induced proliferation inhibition and apoptosis in SW480 and HT29 cells with mutation p53 (Figures 7e and f; Supplementary Figure S7B; Figures 8b and $\mathrm{C}$, left), indicating that mutp53 expression enhanced CRC cells' resistance to $\mathrm{BA}$. Interestingly, BA still effectively induced the expression of p53 target genes (PUMA, P21, NOXA and BIM) after inhibition of p53 in three CRC cells (Supplementary Figure S8). Considering p53 mutation in SW480 and HT29 cells, other proteins may have an important role in BA-induced cell proliferation inhibition and apoptosis in addition to p53.

p53 augmented BA-induced protective autophagy and autophagy flux. As BA treatment downregulated p53, we investigated whether loss of p53 involved in BA-induced autophagy. Interestingly, p53 knockdown attenuated 

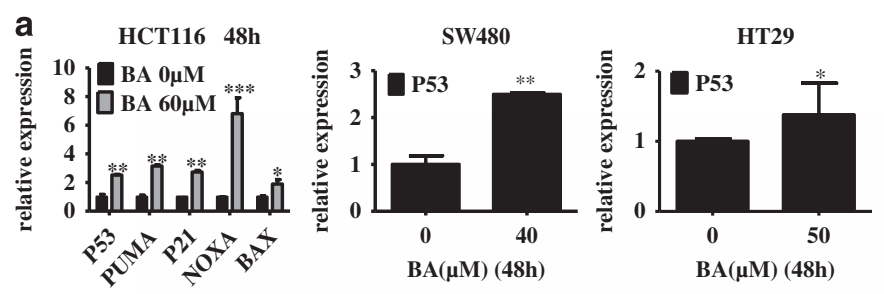

b

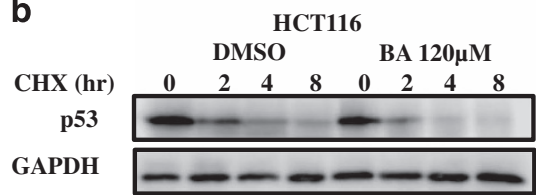

$\begin{array}{lllllllll}\text { p53/GAPDH } \quad 1.00 & 0.31 & 0.26 & 0.16 & 0.84 & 0.25 & 0.12 & 0.05\end{array}$

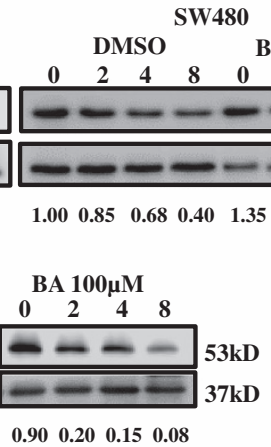

c $\begin{array}{ccc}\text { HCT116 } & \text { SW480 } & \text { HT29 } \\ \text { DMSO MG132 } & \text { DMSO MG132 } & \text { DMSO MG132 }\end{array}$ $\begin{array}{cccccccccccccccc}\mathrm{BA}(\mu \mathrm{M}) & 0 & 60 & \mathbf{0} & \mathbf{6 0} & \mathbf{0} & \mathbf{4 0} & \mathbf{0} & \mathbf{4 0} & \mathbf{0} & \mathbf{5 0} & \mathbf{0} & \mathbf{5 0} & \mathbf{2 0} & \mathrm{h}\end{array}$ p53 - $-2-\infty-\infty$ GAPDH $-\infty-\infty-\infty \mathrm{kD}$

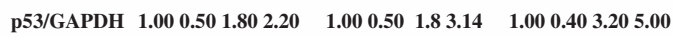

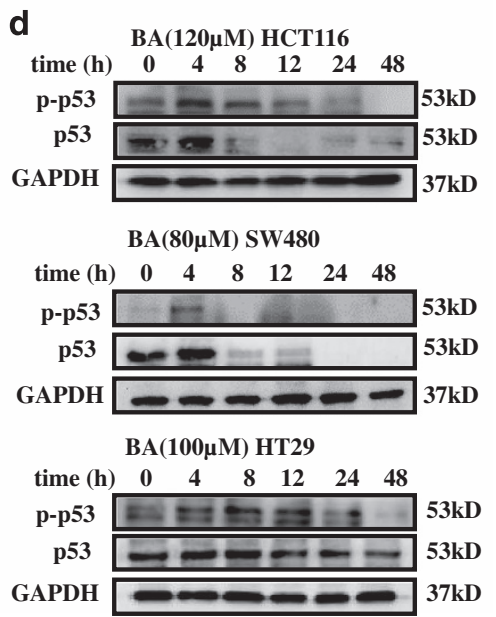

Figure 6 BA first activated and then rapidly degraded p53 by the ubiquitin-proteasome pathway in mutp53 and wtp53 harboring CRC cells. (a) HCT116, SW480 and HT29 cells were treated with BA at the indicated concentrations for $48 \mathrm{~h}$, and then mRNA levels of P53, PUMA, P21, NOXA and BAX in HCT116 cells and mRNA levels of P53 in SW480 and HT29 were determined by qRT-PCR. (b) HCT116, SW480 and HT29 cells were treated with $\mathrm{CHX}(100 \mu \mathrm{g} / \mathrm{ml})$ and/or BA at the indicated concentrations for the indicated time, and then the p53 level was detected by immunoblotting. GAPDH was used as an internal control. The ratio between GAPDH and p53 quantification was determined by Image Lab. (c) HCT116, SW480 and HT29 cells were treated with BA and/or MG132 $(20 \mu \mathrm{M})$ for $20 \mathrm{~h}$, an inhibitor of proteasome, and then the p53 protein level was detected by immunoblotting. GAPDH was used as an internal control. The ratio between GAPDH and p53 quantification was determined by Image Lab. DMSO was the control group. (d) HCT116, SW480 and HT29 cells were treated with BA at the indicated concentrations at times of 0, 4, 8, 16, 24 and $48 \mathrm{~h}$. Then, p53 and phosphorylation p53 at S15 were determined by immunoblotting. GAPDH was internal control. DMSO was the control group

BA-induced LC3-II expression (Figures 8a-C, left) and inhibited BA-induced accumulation of GFP-LC3 puncta in CRC cells (Figures $8 d-f$, left). p53 overexpression increased BA-induced LC3-II expression (Figures $8 \mathrm{a}-\mathrm{C}$, middle) and GFP-LC3 puncta in HCT116 p53-/-, SW480 and HT29 cells (Figures $8 \mathrm{~d}-\mathrm{f}$, right). In addition, BA-induced LC3-II protein expression in HCT116 p53+/+ was more than that in BA-treated HCT116 p53-/- cells (Supplementary Figure S9A) and endogenic LC3 puncta in p53-knockdown HCT116 and HT29 cells also decreased compared with the control group (Supplementary Figure S9B). To determine the role of p53 in BA-induced autophagy flux in CRC cells, a tandem monomeric RFP-GFP-tagged LC3 was used to measure the rate of delivery of autophagosomes to lysosomes. The results showed that BA increased the numbers of both autophagosomes and autolysosomes in CRC cells, which was heightened by p53 overexpression or was restored by silencing p53 (Supplementary Figure S10-S12). These results were confirmed by the evidence that p53 overexpression resulted in further increased $B A$-induced LC3-II conversion, while p53 silencing inhibited BA-induced LC3-II conversion in the presence or absence of $\mathrm{CQ}$ (Supplementary Figure S13). These results demonstrated that p53 could enhance BA-induced autophagy and autophagy flux.

Notably, low dose of ectopic p53 overexpression enhanced BA-induced protective autophagy, whereas high dose of p53 overexpression would reduce BA-induced LC3 conversion (Supplementary Figure S14). In addition, it is known that several miRNAs (e.g., miR34a, miR-218 and miR-502) were involved in p53-mediated cell cycle regulation, autophagy and apoptosis in CRC cells. ${ }^{64-66}$ Interestingly, we found that BA treatment can induce miR-218 expression in three CRC cells, as well as significantly enhance miR-502 expression in HCT116 and HT29 cells and slightly accumulate miR-502 in SW480 cells (Supplementary Figure S15). These lines of evidence suggested that p53-associated non-coding miRNAs were involved in regulating BA-induced apoptosis and autophagy.

BA improves chemotherapeutic response in mutp53 CRC cells by degrading mutp53. Many studies proved that high expression levels of mutp53 proteins in cancer cells have acquired GOF that actively contribute to cancer development progression, and mutp53 depletion in human cancer cells caused chemosensitization toward an array of conventional genotoxic drugs. ${ }^{44,45,67}$ Both BA-induced mutp53 degradation and its associated inhibition of protective autophagy can improve sensitivity of mutp53 cancer cells in response to drug treatment. Our results also found that mutp53 cells (SW480 and HT29) were much more sensitive to BA than wild-type p53 cells (HCT116; Figures 1a and b). Therefore, we asked whether pharmacological degradation of mutp53 by BA could also mediate chemosensitization in response to conventional 
a

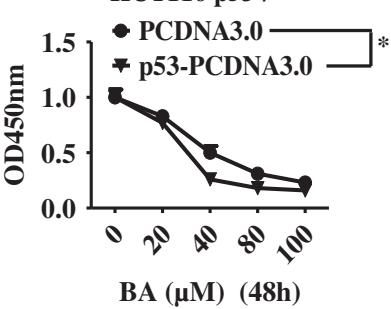

C

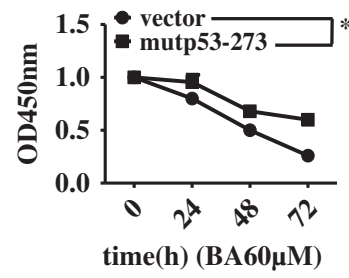

e

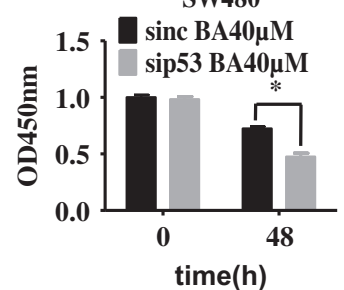

HCT116

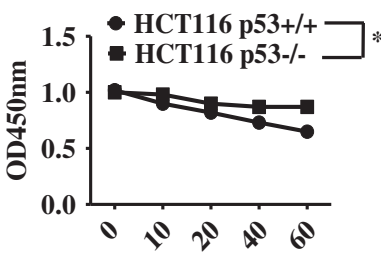

BA( $(\mu \mathrm{M})(48 \mathrm{~h})$
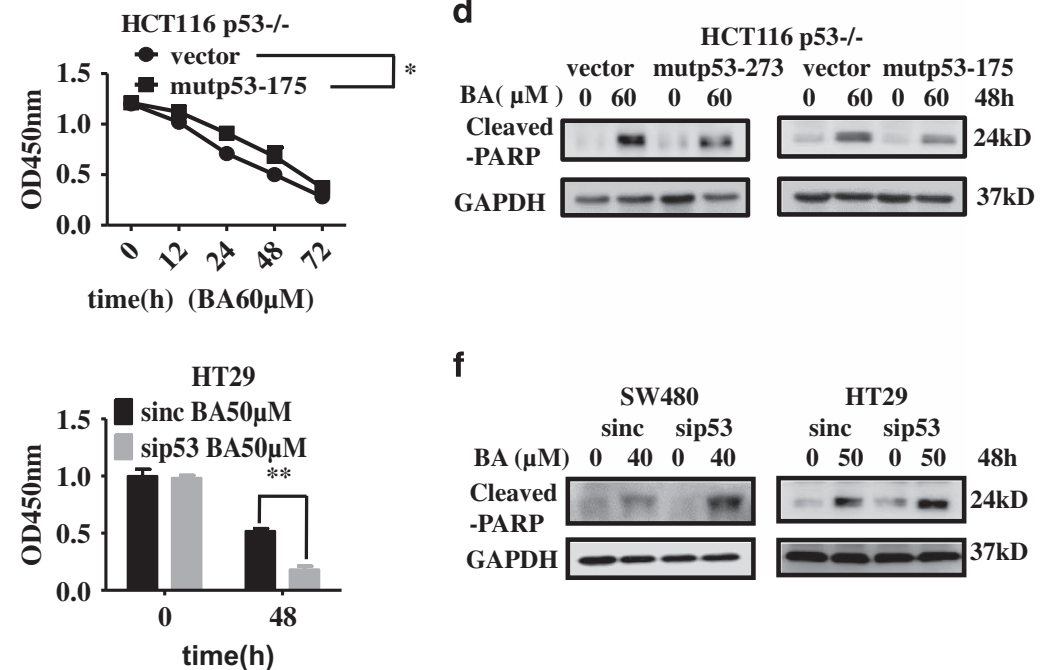

d

$\mathbf{f}$

b

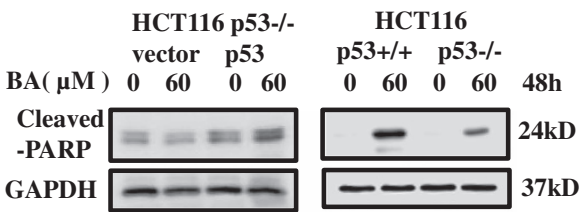

GAPDH ----

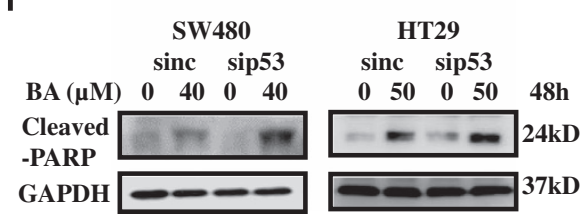

Figure 7 p53 was involved in BA-induced cell proliferation inhibition and apoptosis in CRC cells. (a and $\mathbf{b})$ Left, HCT116 p53 - / cells were transfected with DNA-p53 or control vector for $48 \mathrm{~h}$, and were incubated with the indicated concentrations of BA or control (DMSO) for another $48 \mathrm{~h}$. Cell viability was detected by CCK8 kit in 96 -well plates and whole-cell lysates from six-well plates were collected to analyze the indicated proteins by immunoblotting. Right, HCT116 p53+/+ and p53-/ - cells were treated with the indicated concentrations of BA or control (DMSO) for $48 \mathrm{~h}$. Cell viability was detected by CCK8 kit in 96-well plates and whole-cell lysates from six-well plates were collected to analyze the indicated proteins by immunoblotting. (c and d) HCT116 p53 - / - cells were transfected with DNA-mutp53-R273H, DNA-mutp53-R175H or control vector for 48 h, and were incubated with $60 \mu \mathrm{M}$ of BA or control (DMSO) for another $48 \mathrm{~h}$. Cell viability was detected by CCK8 kit in 96-well plates and whole-cell lysates were collected to analyze the indicated proteins by immunoblot. (e and f) SW480 and HT29 cells were transfected with siRNA specific to p53 and negative control for $24 \mathrm{~h}$, and then treated with BA at 40 or $50 \mu \mathrm{M}$ for another $48 \mathrm{~h}$. Cell proliferation was measured by CCK8 kit in 96-well plates and whole-cell lysates were collected to analyze the indicated proteins by immunoblotting. Data are shown as means \pm S.D. (Student's $t$-test). ${ }^{*} P<0.05,{ }^{* \star} P<0.01$. DMSO was the control group

genotoxic drugs such as 5-FU and Doxorubicin. Results showed that both DOX and 5-Fu induced p53 expression and phosphorylation at Ser15, which could be declined by BA treatment at $10 \mu \mathrm{M}$. Moreover, as expected, $10 \mu \mathrm{M}$ BA, which alone did not induce apparent cell death, synergizing with 5FU or Doxorubicin caused more cell deaths in mutp53 cells (SW480 cells) in contrast with wtp53 cells (HCT116) (Figures $9 \mathrm{a}$ and b). These results suggested that BA could improve other chemotherapeutic drugs partly dependent on degraded mutated p53 in CRC cells.

\section{Discussion}

BA is a bioactive pentacyclic lupine-type triterpenoid natural compound that exhibits anticancer properties. ${ }^{4,6,8,9}$ Here, we reported that $\mathrm{BA}$ exerted its anticancer effect by triggering cell proliferation inhibition and apoptosis in CRC cells. In addition, BA induced a protective autophagy by inhibiting the AKTMTOR signaling pathway, and p53 can further augment this autophagy in CRC cells. To avoid the overaccumulation of protective autophagy, BA would degrade both wtp53 and mutp53, which makes preferential cytotoxicity of BA to mutp53 cells.

Autophagy is a tightly regulated catabolic process of cellular self-digestion by which cellular components are targeted to lysosomes for their degradation. ${ }^{25}$ In response to cancer therapy, autophagy has four faces of function, which are characterized as cytoprotective, cytotoxic, cytostatic and nonprotective. ${ }^{30}$ It was demonstrated that BA blocked autophagic flux in KM3 cells and the inhibition of autophagic flux contributed to BA-mediated apoptosis of $\mathrm{KM} 3$ cells. $^{7}$ In addition, autophagy was also activated as a response to the mitochondria damage inflicted by $B A$, which served as a rescue pathway in HeLa, MCF7, A549 and SW480 cells. ${ }^{10}$ However, B10, a new glycosylated derivative of BA, induced autophagy and abrogated the autophagic flux. By concomitant induction of autophagy and inhibition of the autophagic flux, B10 turns autophagy into a cell death mechanism. ${ }^{36}$ Moreover, another research showed that BA decreased phosphorylation of AKT and degraded EGFR in company with induction of autophagy in bladder cancer, which also resulted in autophagic cell death. ${ }^{68}$ In our study, we found BA-induced 
a

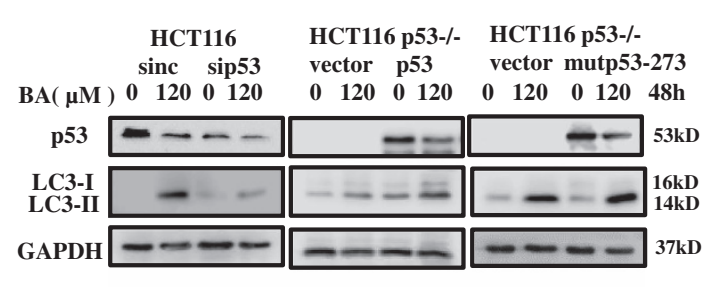

b

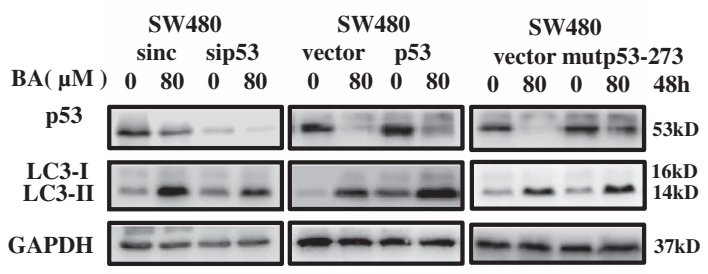

C

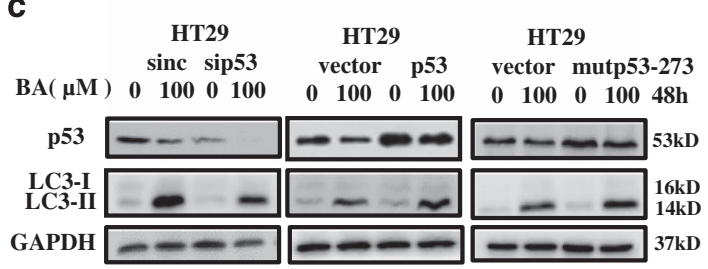

d $\quad$ HCT116 $\mathrm{p53+/+}$
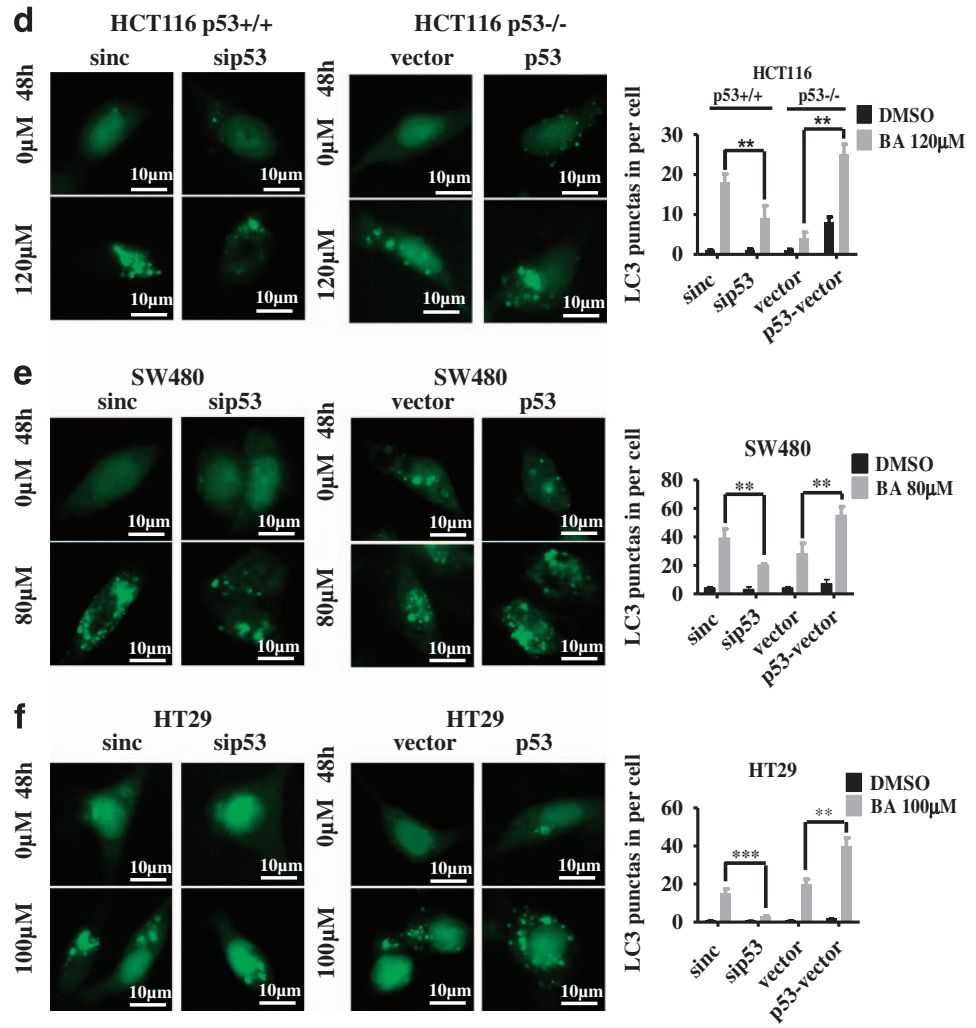

Figure 8 p53 can augment BA-induced autophagy. (a-c) Left, HCT116, SW480 and HT29 cells were transfected with siRNA targeting p53 and negative control for $24 \mathrm{~h}$, and then were incubated with or without BA at the indicated concentrations for another $48 \mathrm{~h}$. The protein levels of p53, LC3 and internal control (GAPDH) were analyzed by immunoblot. (a-c) Middle, HCT116 p53 - / - SW480 and HT29 cells were transfected with DNA-p53 and control vector for $48 \mathrm{~h}$ and then incubated with or without the indicated concentrations of BA for another $48 \mathrm{~h}$. The protein levels of p53, LC3 and internal control (GAPDH) were analyzed by immunoblotting. (a-c) Right, HCT116 p53 - / - , SW480 and HT29 cells were transfected with DNA-mutp53-R273H and control vector for $48 \mathrm{~h}$ and then were incubated with or without the indicated concentrations of BA for another $48 \mathrm{~h}$. The protein levels of p53, LC3 and internal control (GAPDH) were analyzed by immunoblotting. (d-f) Left, HCT116, SW480 and HT29 cells were transfected with siRNA targeting p53 and negative control for $24 \mathrm{~h}$, and then were transfected with GFP-LC3 vector for another $24 \mathrm{~h}$, and finally incubated with or without the indicated concentrations of BA for $48 \mathrm{~h}$. GFP-LC3 puncta was observed with a high-magnification fluorescence. DMSO was control. (d-f) Right, HCT116 p53 - / - SW480 and HT29 cells were co-transfected with DNA -p53 and GPF-LC3 or control vector and GFP-LC3 for $48 \mathrm{~h}$, and then were treated with the indicated concentrations of BA for another $48 \mathrm{~h}$. GFP-LC3 puncta was observed with a high-magnification fluorescence. DMSO was the control group

autophagy by reducing phosphorylation of AKT and MTOR in CRC cells, and autophagy inhibition caused more cell death, indicating that BA-induced autophagy by AKT-MTOR signaling has a cytoprotective effect in CRC cells.

p53 has been linked with regulation of autophagy. ${ }^{47,51,69}$ However, the exact nature of this link remains seemingly controversial. It has been reported that nuclear p53 facilitates autophagy by trans-activating its target genes, whereas cytoplasmic p53 mainly inhibits autophagy by transcriptionindependent mechanisms. ${ }^{52}$ However, these previous observations exclusively reached by p53 or mutp53 overexpression assays are not confirmed by our investigation. Indeed, we revealed that p53 overexpression enhanced BA-induced autophagy, whereas p53 depletion had the contrasting effect, which indicated p53 augmented BA-induced protective autophagy. Besides that, it is also worth mentioning another finding in our study that low overexpression of p53 increased BA-induced autophagy, whereas high overexpression of p53 decreased BA-induced autophagy (Supplementary Figure S14). It may be explained that BA cannot effectively regulate the function of p53 when exogenetic p53 overexpression exceeds a certain amount and p53 may inhibit autophagy by other signaling processes, which is not directly dependent on BA treatment. Autophagy can be regulated by p53-associated non-coding RNAs (for example, miR34a, miR-218 and miR-502). ${ }^{65,70-72}$ In this study, we found that BA treatment induced miR-218 expression in three CRC cells, whereas it significantly enhanced miR-502 expression in HCT116 and HT29 cells and slightly augmented it in SW480 cells (Supplementary Figure S15). miR-218 has been observed to induce CRC cell apoptosis by inducing p53 expression $^{64}$ and AKT-mTOR inhibition, which is a major pathway to regulate autophagy. ${ }^{73}$ However, miR-502, which could inhibit autophagy in CRC cells, had potential p53binding sites in their putative promoter regions and was regulated by $\mathrm{p} 53$ via a negative feedback regulatory mechanism. ${ }^{65,74}$ Therefore, it is possible that BA upregulates miR-218 to induce p53 within a short-time treatment and p53 degradation may increase miR-502, which will inhibit protective autophagy overaccumulation.

As we all know, wtp53 as a tumor suppressor protein has been implicated in apoptosis. ${ }^{69}$ It was reported that BA triggered apoptosis without activation of p53 in neuroectodermal and breast cancers. ${ }^{53,75}$ Thus, it undoubtedly prompted us 

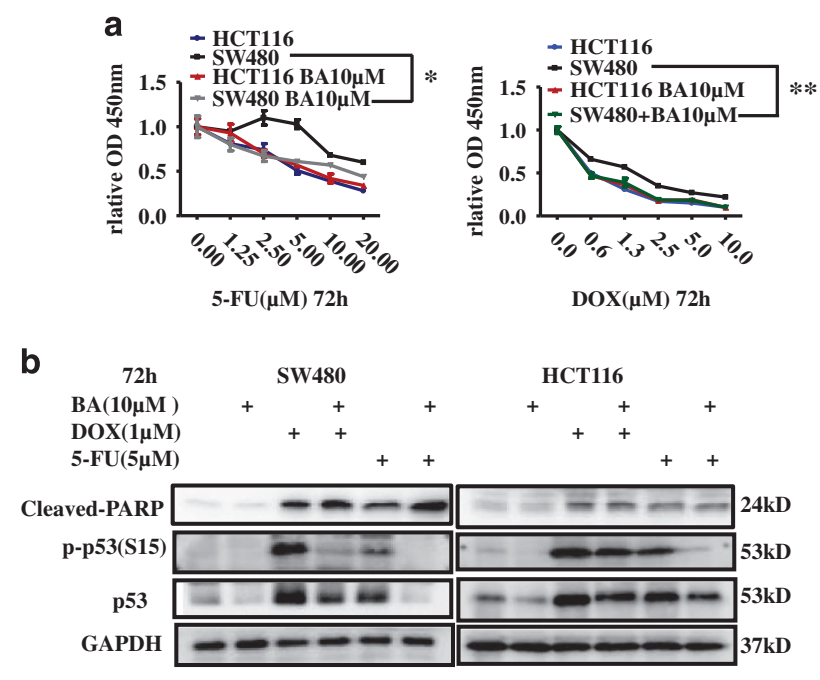

Figure 9 BA improves chemotherapeutic response in mutp53 CRC cells. (a) Left, HCT116 and SW480 were treated with 5-FU alone or 5-FU in combination with BA $(10 \mu \mathrm{M})$ for $72 \mathrm{~h}$. Then, cell viability was analyzed by CCK8 kit. Right, HCT116 and SW480 were treated with ADR alone or ADR in combination with $\mathrm{BA}(10 \mu \mathrm{M})$ for $72 \mathrm{~h}$. Then, cell viability was analyzed by CCK8 kit. Data are shown as means \pm S.D. ( $n=6$, Student's t-test). ${ }^{*} P<0.05,{ }^{* *} P<0.01$. (b) SW480 and HCT116 cells were treated with 5-FU or ADR at the indicated concentrations alone or in combination of $\mathrm{BA}(10 \mu \mathrm{M})$ for $72 \mathrm{~h}$, respectively. Whole-cell lysates were collected and the indicated proteins were analyzed by immunoblotting. GAPDH was used as internal control. DMSO was the control group

to question why and how BA treatment affects p53 expression in CRC cells. We found that BA firstly induced the expression and activation of p53 and then rapidly degraded p53 in both wtp53 and mup53 CRC cells (Figure 6d). In addition, BA further promoted protective autophagy and apoptosis in HCT116 p53+/+ cells compared with HCT116 p53 - / - cells (Figure $7 \mathrm{~b}$ and $8 \mathrm{a}$; Figure $8 \mathrm{a}$, middle and $8 \mathrm{D}$, right; Supplementary Figure S9A), which maybe because that BA activates p53 till $12 \mathrm{~h}$ to induce apoptosis in HCT116 p53+/+ cells and then rapidly degraded p53 to inhibit protective autophagy, but the early stage of BA-induced p53 expression has a stronger effect on apoptosis than BA-induced and p53enhanced protective autophagy. Moreover, mutp53 transfection enhanced BA-induced autophagy and inhibited the sensitivity of HCT116 p53-/ - to BA (Figures 7c and d), whereas mutp53 silencing in mutp53-harbored SW480 and HT29 cells inhibited BA-induced protective autophagy and augmented BA-induced apoptosis (Figure $7 f$ and Supplementary Figure S7B), suggesting that this mutp53promoted and BA-induced autophagy have a role in mutp53induced BA resistance in CRC cells. In addition, BA upregulated p53 target gene in the presence or absence of p53 in mutp53 and wtp53 CRC cells (Figure 6a and Supplementary Figure S8), suggesting that alternative pathways apart from p53 are involved in BA-induced upregulation of p53 target gene.

There is growing evidence that mutp53 is a clinically relevant target for intervention. ${ }^{76}$ The hyperstability of mutp53 (including p53R273H mutants in HT29 and p53R273H/P309S mutants in SW480) is the basis for its GOF and dominant negativity that promotes malignancy and chemoresis-

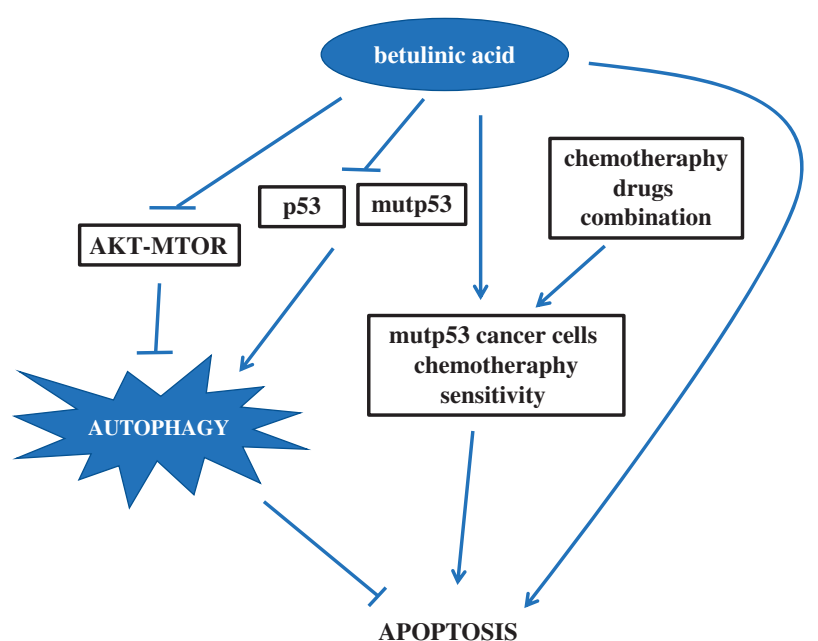

Figure 10 Model of the molecular mechanism unraveled in the presented study. BA induced a protective autophagy by inhibiting AKT-MTOR signaling and degraded p53 to attenuate this protective autophagy overaccumulation, which makes BA acting as one attractive drug in combining with other chemotherapy agents to treat mutp53 CRC cells

tance. ${ }^{39,40,45,67}$ mutp53 is more resistant to proteasomedependent degradation compared with wtp53, but the exact identity of the pathway is still on debate. ${ }^{38,40}$ Thus, preventing mutp53 accumulation provides an important chemopreventive and chemotherapeutic strategy. Our study showed that BA preferentially degraded mutp53 through the ubiquitin-proteasome pathway (Figure 6c), indicating that BA treatment may overcome some forms of drug resistance in mutp53 cancers. It has been reported that cytotoxic drugs are given in combinations to enhance their antitumor effectiveness during polychemotherapy. ${ }^{77}$ To this end, we further investigated the application of BA combination in clinical therapy and found that low concentrations of BA combination with chemotherapy drugs such as $5-\mathrm{FU}$ and DOX further caused cell killing than chemotherapy drug treatment alone in mutp 53 cancer cells by partly inducing mutp53 degradation (Figures 9a and b), indicating that BA may have an increased therapeutic effect on mutp53-harboring cancers in clinical application.

Overall, this study highlights that BA induced a protective autophagy by inhibiting AKT-MTOR signaling. In addition, BA firstly activated and then rapidly degraded p53 to attenuate this protective autophagy, which makes BA act as one attractive drug in combination with other chemotherapy agents to treat mutp53 CRC cells (Figure 10). Our findings revealed that $\mathrm{BA}$ induced $\mathrm{CRC}$ cell death and $\mathrm{BA}$ reduced the incidence of mutp53 cancer chemotherapy resistance by degrading mutp53 may have important implications if used for cancer therapy.

\section{Materials and Methods}

Cells and cell culture. Human colorectal cancer HCT116 (wtp53) cells, SW480 (p53R273H/P309S) cells and HT29 (p53R273H) cells were purchased from Shanghai Cell Bank in China. Cells were maintained in DMEM (HyClone, Logan, UT, USA) supplemented with $10 \%$ heat-inactivated fetal bovine serum (GIBCO, Carlsbad, CA, USA), penicillin and streptomycin (Hyclone). All cells were maintained in a humidified $5 \% \mathrm{CO}_{2}$ atmosphere at $37^{\circ} \mathrm{C}$. 
Reagents and antibodies. BA (Meilunbio, Dalian, China; MB5971), Chloroquine (Sigma, St. Louis, MO, USA; C6628), E-64d (Sigma, E8640) and Pepstain A (Sigma, P4265) were dissolved in DMSO (Sigma, D2650). Acridine orange (Sigma, A6014) and 3-MA (Meilunbio, MB5063) were dissolved in PBS. MG132 (Meilunbio, MB5137), Etoposide (Meilunbio, MB1102-S) and CHX (Meilunbio, MB2208) were dissolved in DMSO. LC3 (MBL, Beijing, China; PM036) was bought for immunoblot or immunofluorescence analysis. Antibodies including AKT, phosphorylation of AKT (Ser473; 4060), MTOR, phosphorylation of MTOR (Ser2443; 5535), PARP (116 and $89 \mathrm{kd}$; 9542S), BAX (5023), phosphorylation of p53 (Ser15; 9286) and GAPDH (Santa Cruz Biotechnology(CA, USA) 5174) were purchased from CST (Beverly, MA, USA). Cleaved-PARP antibody was purchased from Sigma (SAB4500487). p53 (SC-126) and LAMP1 (SC-5570) were purchased from Santa Cruz Biotechnology (CA, USA) for immunoblot or immunofluorescence analyses.

Cell proliferation assays. Overall, $1.0 \times 10^{4}$ cells were seeded in 96-well plates and incubated at $37^{\circ} \mathrm{C}$ for $24 \mathrm{~h}$, followed by treatment with $\mathrm{BA}$ at indicated concentrations for another $48 \mathrm{~h}$. After BA treatment, CCK8 reagents (Dojindo, Kamimashiki-gun, Kumamoto, Japan; CK04) were added and co-incubated for $1 \mathrm{~h}$. The absorbance value was then measured at wavelength $450 \mathrm{~nm}$.

Detection of apoptosis. Overall, $1.0 \times 10^{6}$ cells were seeded in six-well plates and incubated at $37^{\circ} \mathrm{C}$ for $24-48 \mathrm{~h}$, and then the fresh medium containing $\mathrm{BA}$ or the mixture of BA and autophagy inhibitors at indicated concentration for $48 \mathrm{~h}$ were replaced. According to the recommended protocol, the apoptosis rates were analyzed by Annexin-V-FITC and PI double-staining method based on the apoptosis detection kit (Beyotime Biotechnology, Shanghai, China) through flow cytometry (BD Biosciences, San Jose, CA, USA).

DAPI staining assay. Cells were cultured in six-well plates with indicated concentrations of BA for $48 \mathrm{~h}$. Then, cells were washed with PBS once and fixed by $4 \%$ paraformaldehyde for $15 \mathrm{~min}$. Subsequently, DAPI diluted by PBS $(1: 20)$ was added into each well for $10 \mathrm{~min}$ following by washing with PBS for $10 \mathrm{~min}$ twice, and the bluestained nuclei in cells were observed with fluorescence microscopy immediately.

Transmission electron microscopy. For TEM observation, cells were treated with DMSO and $60 \mu \mathrm{M}$ BA for $48 \mathrm{~h}$. The methods of TEM detection was previously described in detail. ${ }^{78}$

Detection of AVOs. Cells were seeded on coverslips in 24-well plates and were allowed to attach by overnight incubation. Following treatment with DMSO (control) or BA at indicated concentrations, cells were stained with $1 \mu \mathrm{g} / \mathrm{ml}$ acridine orange in PBS for $15 \mathrm{~min}$, washed with PBS and examined under highmagnification fluorescence microscope (Olympus Optical Co., Hamburg, Germany).

Transfection. All siRNAs were chemically synthesized by GenePharma company (Shanghai, China). The sequences of the siRNAs used are listed in Supplementary Table 1. The siRNAs were transfected into the indicated cells using Lipofectamine RNAiMAX reagent (Invitrogen, Carlsbad, CA, USA) according to the manufacturer's instructions. Cells were then collected and subjected to analysis 24-72 $\mathrm{h}$ after transfection. The experiments were repeated at least three times. Vectors were transfected by using Lipofectamine 2000 reagents (Invitrogen) according to the manufacturer's instructions for $48 \mathrm{~h}$, and then cells were incubated with $\mathrm{BA}$ at indicated concentrations.

GFP-LC3 and GFP-RFP-LC3 spot detection. First, cells were seeded on coverslips in 24-well plates and were allowed to attach by overnight incubation. GFP-LC3 or GFP-RFP-LC3 vectors were transfected in HCT116, SW480 and HT29 cells, respectively, for $24 \mathrm{~h}$, following treatment with DMSO (control), or BA for $48 \mathrm{~h}$. After depletion of the medium, cells were washed with PBS three times, fixed by $4 \%$ paraformaldehyde for $15 \mathrm{~min}$, washed with PBS three times and photographed with a high-magnification fluorescence microscope (Olympus Optical Co.).

Immunofluorescence and colocalization analysis. Cells were seeded on coverslips in 24-well plates and were allowed to attach by overnight incubation following treatment with DMSO (control) or BA at indicated concentrations for $48 \mathrm{~h}$. Cells were fixed in $4 \%$ paraformaldehyde at $4{ }^{\circ} \mathrm{C}$ for $15 \mathrm{~min}$, permeabilized with $0.01 \%$ Triton X-100 for 5 min and then blocked with $10 \%$ BSA for $1 \mathrm{~h}$. Cells were incubated with primary Ab (rabbit anti-human LC3 or/and LAMP1, diluted $1: 200$, respectively) overnight, and then incubated with secondary $\mathrm{Ab}$ (Alexa fluor 594 goat anti-rabbit or/and Alexa fluor 488 goat anti-mouse) for $1 \mathrm{~h}$.
Unbound Ab was removed with PBS; thereafter, cell nuclei were stained with DAPI $(1: 20)$. The samples were examined under a high-magnification fluorescence microscope (Olympus Optical Co.).

Quantitative RT-PCR. Total RNA was extracted from cells treated with BA at indicated concentration or was transfected with siRNA or vectors by using Trizol reagent (Invitrogen). cDNA reverse transcription and qRT-PCR were performed as the instruction indication of Reverse Transcription PrimeScript 1st Stand cDNA Synthesis kit (TaKaRa, Otsu, Japan) and quantitative PCR reagents SYBR PremixEx TaqTM (TaKaRa). The relative expression of genes was calculated with the $2^{-\Delta \Delta C t}$ method. The sequences of the primers used are presented in Supplementary Table 2.

MicroRNA RT-PCR. Total RNA was extracted from cultured three CRC cells by using Trizol reagent (Invitrogen). The expression level of matured miRNAs was analyzed by stem-loop reverse transcription followed by PrimeScript RT Reagent Kit (Takara). MicroRNA expression was normalized to the endogenous reference gene, U6. qPCR was performed by using SYBR PremixEx Taq-II (TaKaRa). The $2^{-\Delta \Delta C T}$ method was used to quantify the expression changes of target genes. Three independent experiments were carried out. The primers used were listed in Supplementary Tables 3 and 4.

Immunoblot analysis. After treatment with BA, the cells were collected, washed with ice-cold PBS and then extracted into ice-cold protein lysates RIPA or SDS buffer (Beyotime Biotechnology, Shanghai, China) with $1 \mathrm{mM}$ PMSF (Hangzhou Beyotime Biotechnology). After being sonicated, the cells were centrifuged at $12000 \times \mathrm{g}$ for $15 \mathrm{~min}$ at $4^{\circ} \mathrm{C}$. The protein concentration was determined using a bicinchoninic acid protein assay kit (Bio-Rad, Hercules, CA, USA) according to the manufacturer's instructions. Equivalent amounts of protein samples and $4 \mu \mathrm{l}$ pre-stained protein markers were uploaded, separated by $8-15 \%$ polyacrylamide gel electrophoresis, and then were transferred onto PVDF membranes (Millipore, Bedford, MA, USA). The membranes were blocked in $5 \%$ (w/v) skimmed milk, or in 5\% (w/v) BSA only for p-AKT, p-MTOR and p-p53 protein, dissolving in TBS-T at room temperature for $2 \mathrm{~h}$ and then incubated with dilution of appropriate antibodies according to antibody specification overnight at $4^{\circ} \mathrm{C}$, followed by incubation with goat anti-rabbit or anti-mouse horseradish peroxidaseconjugated secondary antibody at room temperature for $1 \mathrm{~h}$. The blots were visualized by using chemiluminescent substrates (Millipore).

Statistical analysis. Multiple comparisons of IC50 were performed by repeated measures ANOVA and Bonferroni's test using GraphPad Prism 5 Software (La Jolla, CA, USA). Student's (two-tailed) $t$-test was also conducted. $P$-value $<0.05$ was marked as statistically significant. $P$-value $<0.01$ was indicated as highly statistically significant. $P$-value $<0.001$ was indicated as extremely statistically significant difference. Values are the means of three independent experiments (means $\pm S D$ ).

\section{Conflict of Interest}

The authors declare no conflict of interest.

Acknowledgements. This work was supported by the National Natural Science Foundation of China (81401951 to YL, 81401889 to HZ, and 81501979 to $\mathrm{CZ}$ ), Chongqing Natural Science Foundation (cstc2016jcyjA0227 to $\mathrm{YL}$ ), and Scientific and Technological Research Program of Chongqing Municipal Education Commission (KJ1400207 to YL).

\section{Publisher's Note}

Springer Nature remains neutral with regard to jurisdictional claims in published maps and institutional affiliations.

1. Siegel RL, Miller KD, Fedewa SA, Ahnen DJ, Meester RGS, Barzi A et al. Colorectal cancer statistics, 2017. CA Cancer J Clin 2017; 67: 177-193.

2. Siegel R, Desantis C, Jemal A. Colorectal cancer statistics, 2014. CA Cancer J Clin 2014; 64: 104-117.

3. Garg AK, Buchholz TA, Aggarwal BB. Chemosensitization and radiosensitization of tumors by plant polyphenols. Antioxidants Redox Signal 2005; 7: 1630-1647.

4. Tolstikova TG, Sorokina IV, Tolstikov GA, Tolstikov AG, Flekhter OB. Biological activity and pharmacological prospects of lupane terpenoids: I. Natural lupane derivatives. Bioorg Khim 2006; 32: 42-55. 
5. Newman DJ, Cragg GM. Natural products as sources of new drugs over the 30 years from 1981 to 2010. J Nat Prod 2012; 75: 311-335.

6. Mullauer FB, Kessler JH, Medema JP. Betulinic acid, a natural compound with potent anticancer effects. Anticancer Drugs 2010; 21: 215-227.

7. Yang LJ, Chen Y, He J, Yi S, Wen L, Zhao J et al. Betulinic acid inhibits autophagic flux and induces apoptosis in human multiple myeloma cells in vitro. Acta Pharmacol Sin 2012; 33 : $1542-1548$.

8. Jonnalagadda SC, Corsello MA, Sleet CE. Betulin-betulinic acid natural product based analogs as anti-cancer agents. Anticancer Agents Med Chem 2013; 13: 1477-1499.

9. Gheorgheosu D, Duicu O, Dehelean C, Soica C, Muntean D. Betulinic acid as a potent and complex antitumor phytochemical: a minireview. Anticancer Agents Med Chem 2014; 14 : 936-945.

10. Potze L, Mullauer FB, Colak S, Kessler JH, Medema JP. Betulinic acid-induced mitochondria-dependent cell death is counterbalanced by an autophagic salvage response. Cell Death Dis 2014; 5: e1169.

11. Frolova TS, Kukina TP, Sinitsyna OI. Genotoxic and mutagenic properties of synthetic betulinic and betulonic acids. Bioorg Khim 2015; 41: 462-467.

12. Khan I, Guru SK, Rath SK, Chinthakindi PK, Singh B, Koul S et al. A novel triazole derivative of betulinic acid induces extrinsic and intrinsic apoptosis in human leukemia $\mathrm{HL}-60$ cells. Eur J Med Chem 2016; 108: 104-116.

13. Xu T, Pang Q, Zhou D, Zhang A, Luo S, Wang Y et al. Proteomic investigation into betulinic acid-induced apoptosis of human cervical cancer HeLa cells. PLOS ONE 2014; 9: e105768.

14. Gayathri C, Indira J, Robert B, Stephen S. Drugs that target specificity proteins downregulate epidermal growth factor receptor in bladder cancer cells. Mol Cancer Res 2010; 8: 739-750.

15. Mullauer FB, Bloois Lv, Daalhuisen JB, Brink MST, Storm G, Medema JP et al. Betulinic acid delivered in liposomes reduces growth of human lung and colon cancers in mice without causing systemic toxicity. Anticancer Drugs 2011; 22: 223-233.

16. Zuco V, Supino R, Righetti SC, Cleris L, Marchesi E, Gambacorti-Passerini C et al. Selective cytotoxicity of betulinic acid on tumor cell lines, but not on normal cells. Cancer Lett 2002; 175: 17-25.

17. Pisha E, Chai H, Lee IS, Chagwedera TE, Farnsworth NR, Cordell GA et al. Discovery of betulinic acid as a selective inhibitor of human melanoma that functions by induction of apoptosis. Nat Med 1995; 1: 1046-1051.

18. Kessler JH, Mullauer FB, de Roo GM, Medema JP. Broad in vitro efficacy of plant-derived betulinic acid against cell lines derived from the most prevalent human cancer types. Cancer Lett 2007; 251: 132-145.

19. Gonzalez P, Mader I, Tchoghandjian A, Enzenmüller S, Cristofanon S, Basit F et al. Impairment of lysosomal integrity by B10, a glycosylated derivative of betulinic acid, leads to lysosomal cell death and converts autophagy into a detrimental process. Cell Death Differ 2012; 19: 1337-1346.

20. Jung GR, Kim KJ, Choi CH, Lee TB, Han SI, Han HK et al. Effect of betulinic acid on anticancer drug-resistant colon cancer cells. Basic Clin Pharmacol Toxicol 2007; 101: 277-285.

21. Chintharlapalli S, Papineni S, Lei P, Pathi S, Safe S. Betulinic acid inhibits colon cancer cell and tumor growth and induces proteasome-dependent and -independent downregulation of specificity proteins (Sp) transcription factors. BMC Cancer 2011; 11: 371.

22. Su D, Gao YQ, Dai WB, Hu Y, Wu YF, Mei QX. Helicteric acid, oleanic acid, and betulinic acid, three triterpenes from Helicteres angustifolia L., inhibit proliferation and induce apoptosis in HT-29 Colorectal cancer cells via suppressing NF-kappaB and STAT3 signaling. Evid Based Complement Alternat Med 2017; 2017: 5180707.

23. Kasperczyk H, La Ferla-Brühl K, Westhoff MA, Behrend L, Zwacka RM, Debatin K-M et al. Betulinic acid as new activator of NF-kappaB: molecular mechanisms and implications for cancer therapy. Oncogene 2005; 24: 6945-6956.

24. Kelekar A. Autophagy. Ann N Y Acad Sci 2005; 1066: 259-271.

25. Lorin S, Hamai A, Mehrpour M, Codogno P. Autophagy regulation and its role in cancer. Semin Cancer Biol 2013; 23: 361-379.

26. Galluzzi L, Pietrocola F, Bravo-San Pedro JM, Amaravadi RK, Baehrecke EH, Cecconi F et al. Autophagy in malignant transformation and cancer progression. EMBO J 2015; 34 856-880.

27. Zhou H, Yuan M, Yu Q, Zhou X, Min W, Gao D. Autophagy regulation and its role in gastric cancer and colorectal cancer. Cancer Biomarkers 2016; 17: 1-10.

28. Nakahira K, Choi AMK. Autophagy: a potential therapeutic target in lung diseases. Am J Physiol 2013; 305: L93-1107.

29. Kroemer G, Marino G, Levine B. Autophagy and the integrated stress response. Mol Cell 2010; 40: 280-293.

30. Gewirtz DA. The four faces of autophagy: implications for cancer therapy. Cancer Res 2014; 74: 647-651.

31. Chen HY, White E. Role of autophagy in cancer prevention. Cancer Prev Res 2011; 4: 973-983.

32. Helgason GV, Holyoake TL, Ryan KM. Role of autophagy in cancer prevention, development and therapy. Essays Biochem 2013; 55: 133-151.

33. Murrow L, Debnath J. Autophagy as a stress-response and quality-control mechanism: implications for cell injury and human disease. Annu Rev Pathol 2013; 8: 105-137.

34. Bristol ML, Di X, Beckman MJ, Wilson EN, Henderson SC, Maiti A et al. Dual functions of autophagy in the response of breast tumor cells to radiation: cytoprotective autophagy with radiation alone and cytotoxic autophagy in radiosensitization by vitamin $\mathrm{D} 3$. Autophagy 2012; 8: 739-753.
35. Wilson EN, Bristol ML, Di X, Maltese WA, Koterba K, Beckman MJ et al. A switch between cytoprotective and cytotoxic autophagy in the radiosensitization of breast tumor cells by chloroquine and vitamin D. Horm Cancer 2011; 2: 272-285.

36. Gonzalez P, Mader I, Tchoghandjian A, Enzenmuller S, Cristofanon S, Basit F et al. Impairment of lysosomal integrity by B10, a glycosylated derivative of betulinic acid, leads to lysosomal cell death and converts autophagy into a detrimental process. Cell Death Differ 2012; 19: 1337-1346.

37. Dutta D, Chakraborty B, Sarkar A, Chowdhury C, Das P. A potent betulinic acid analogue ascertains an antagonistic mechanism between autophagy and proteasomal degradation pathway in HT-29 cells. BMC Cancer 2016; 16: 23.

38. Carvajal LA, Manfredi JJ. Another fork in the road-life or death decisions by the tumour suppressor p53. EMBO Rep 2013; 14: 414-421.

39. Hanel W, Moll UM. Links between mutant p53 and genomic instability. J Cell Biochem 2012 113: $433-439$

40. Wiman KG. Pharmacological reactivation of mutant p53: from protein structure to the cancer patient. Oncogene 2010; 29: 4245-4252.

41. Vousden KH, Lu X. Live or let die: the cell's response to p53. Nat Rev Cancer 2002; 2 594-604

42. Freed-Pastor WA, Prives C. Mutant p53: one name, many proteins. Genes Dev 2012; 26 : 1268-1286.

43. Hanel W, Marchenko N, Xu S, Yu SX, Weng W, Moll U. Two hot spot mutant p53 mouse models display differential gain of function in tumorigenesis. Cell Death Differ 2013; 20. 898-909.

44. Li D, Marchenko ND, Moll UM. SAHA shows preferential cytotoxicity in mutant p53 cancer cells by destabilizing mutant p53 through inhibition of the HDAC6-Hsp90 chaperone axis. Cell Death Differ 2011; 18: 1904-1913.

45. Bossi G, Lapi E, Strano S, Rinaldo C, Blandino G, Sacchi A. Mutant p53 gain of function: reduction of tumor malignancy of human cancer cell lines through abrogation of mutant p53 expression. Oncogene 2006; 25: 304-309.

46. Joerger AC, Fersht AR. The p53 pathway: origins, inactivation in cancer, and emerging therapeutic approaches. Annu Rev Biochem 2016; 85: 375-404.

47. Tang J, Di J, Cao H, Bai J, Zheng J. p53-mediated autophagic regulation: a prospective strategy for cancer therapy. Cancer Lett 2015; 363: 101-107.

48. Tasdemir E, Chiara Maiuri M, Morselli E, Criollo A, D'Amelio M, Djavaheri-Mergny M et al. A dual role of p53 in the control of autophagy. Autophagy 2008; 4: 810-814.

49. Green DR, Kroemer G. Cytoplasmic functions of the tumour suppressor p53. Nature 2009 458: $1127-1130$

50. Tasdemir E, Maiuri MC, Galluzzi L, Vitale I, Djavaheri-Mergny M, D'Amelio M et al. Regulation of autophagy by cytoplasmic p53. Nat Cell Biol 2008; 10: 676-687.

51. Maiuri MC, Galluzzi L, Morselli E, Kepp O, Malik SA, Kroemer G. Autophagy regulation by p53. Curr Opin Cell Biol 2010; 22: 181-185.

52. White E. Autophagy and p53. Cold Spring Harb Perspect Med 2016; 6: a026120.

53. Fulda S, Friesen C, Los M, Scaffidi C, Mier W, Benedict M et al. Betulinic acid triggers CD95 (APO-1/Fas)- and p53-independent apoptosis via activation of caspases in neuroectodermal tumors. Cancer Res 1997; 57: 4956-4964.

54. Meng RD, El-Deiry WS. p53-independent upregulation of KILLER/DR5 TRAIL receptor expression by glucocorticoids and interferon-gamma. Exp Cell Res 2001; 262: 154-169.

55. Elmore S. Apoptosis: a review of programmed cell death. Toxicol Pathol 2007; 35: 495-516

56. Zhou S, Zhao L, Kuang M, Zhang B, Liang Z, Yi T et al. Autophagy in tumorigenesis and cancer therapy: Dr Jekyll or Mr. Hyde? Cancer Lett 2012; 323: 115-127.

57. Lee JG, Shin JH, Shim HS, Lee CY, Kim DJ, Kim YS et al. Autophagy contributes to the chemo-resistance of non-small cell lung cancer in hypoxic conditions. Respir Res 2015; 16: 138.

58. Cheng Y, Ren X, Hait WN, Yang JM. Therapeutic targeting of autophagy in disease: biology and pharmacology. Pharmacol Rev 2013; 65: 1162-1197.

59. Wang K, Liu R, Li J, Mao J, Lei Y, Wu J et al. Quercetin induces protective autophagy in gastric cancer cells: involvement of Akt-mTOR- and hypoxia-induced factor 1alpha-mediated signaling. Autophagy 2011; 7: 966-978.

60. Pankiv S, Clausen TH, Lamark T, Brech A, Bruun JA, Outzen H et al. p62/SQSTM1 binds directly to Atg8/LC3 to facilitate degradation of ubiquitinated protein aggregates by autophagy. J Biol Chem 2007; 282: 24131-24145.

61. Katsuragi $Y$, Ichimura $Y$, Komatsu M. p62/SQSTM1 functions as a signaling hub and an autophagy adaptor. FEBS J 2015; 282: 4672-4678.

62. Hamacher-Brady A. Autophagy regulation and integration with cell signaling. Antioxidants Redox Signal 2012; 17: 756-765.

63. Wang SY, Yu QJ, Zhang RD, Liu B. Core signaling pathways of survival/death in autophagyrelated cancer networks. Int J Biochem Cell Biol 2011; 43: 1263-1266.

64. He X, Dong Y, Wu CW, Zhao Z, Ng SS, Chan FK et al. MicroRNA-218 inhibits cell cycle progression and promotes apoptosis in colon cancer by downregulating BMl1 polycomb ring finger oncogene. Mol Med 2013; 18: 1491-1498.

65. Zhai H, Song B, Xu X, Zhu W, Ju J. Inhibition of autophagy and tumor growth in colon cancer by miR-502. Oncogene 2013; 32: 1570-1579.

66. Li H, Rokavec M, Jiang L, Horst D, Hermeking H. Antagonistic effects of p53 and HIF1A on microRNA-34a regulation of PPP1R11 and STAT3 and hypoxia-induced epithelial to mesenchymal transition in colorectal cancer cells. Gastroenterology 2017; 153: 505-520.

67. Yue $\mathrm{X}$, Zhao $\mathrm{Y}$, Liu J, Zhang $\mathrm{C}$, Yu $\mathrm{H}$, Wang J et al. BAG2 promotes tumorigenesis through enhancing mutant p53 protein levels and function. eLife 2015; 4: e08401. 
68. Chadalapaka G, Jutooru I, Burghardt R, Safe S. Drugs that target specificity proteins downregulate epidermal growth factor receptor in bladder cancer cells. Mol Cancer Res 2010; 8: 739-750.

69. Sui X, Jin L, Huang X, Geng S, He C, Hu X. p53 signaling and autophagy in cancer: a revolutionary strategy could be developed for cancer treatment. Autophagy 2011; 7 : 565-571.

70. Fu Q, Cheng J, Zhang J, Zhang Y, Chen X, Xie J et al. Downregulation of YEATS4 by miR-218 sensitizes colorectal cancer cells to L-OHP-induced cell apoptosis by inhibiting cytoprotective autophagy. Oncol Rep 2016; 36: 3682-3690.

71. Yin H, Zhang S, Sun Y, Li S, Ning Y, Dong Y et al. MicroRNA-34/449 targets IGFBP-3 and attenuates airway remodeling by suppressing Nur77-mediated autophagy. Cell Death Dis 2017; 8: e2998.

72. Kim NH, Cha YH, Kang SE, Lee Y, Lee I, Cha SY et al. p53 regulates nuclear GSK-3 levels through miR-34-mediated Axin2 suppression in colorectal cancer cells. Cell Cycle 2013; 12 : 1578-1587.

73. Zhang X, Shi H, Tang H, Fang Z, Wang J, Cui S. miR-218 inhibits the invasion and migration of colon cancer cells by targeting the PI3K/Akt/mTOR signaling pathway. Int J Mol Med 2015; 35: 1301-1308.

74. Xi Y, Shalgi R, Fodstad O, Pilpel Y, Ju J. Differentially regulated micro-RNAs and actively translated messenger RNA transcripts by tumor suppressor p53 in colon cancer. Clin Cancer Res 2006; 12(7 Pt 1): 2014-2024.

75. Tiwari R, Puthli A, Balakrishnan S, Sapra BK, Mishra KP. Betulinic acid-induced cytotoxicity in human breast tumor cell lines MCF-7 and T47D and its modification by tocopherol. Cancer Invest 2014; 32: 402-408
76. Bykov VJ, Zhang Q, Zhang M, Ceder S, Abrahmsen L, Wiman KG. Targeting of mutant p53 and the cellular redox balance by APR-246 as a strategy for efficient cancer therapy. Front Oncol 2016; 6: 21.

77. Ehrhardt H, Hofig I, Wachter F, Obexer P, Fulda S, Terziyska N et al. NOXA as critical mediator for drug combinations in polychemotherapy. Cell Death Dis 2012; 3: e327.

78. Zhou Y, Liang X, Chang H, Shu F, Wu Y, Zhang T et al. Ampelopsin-induced autophagy protects breast cancer cells from apoptosis through Akt-mTOR pathway via endoplasmic reticulum stress. Cancer Sci 2014; 105: 1279-1287.

cc (i) Cell Death and Disease is an open-access journal published by Nature Publishing Group. This work is licensed under a Creative Commons Attribution 4.0 International License. The images or other third party material in this article are included in the article's Creative Commons license, unless indicated otherwise in the credit line; if the material is not included under the Creative Commons license, users will need to obtain permission from the license holder to reproduce the material. To view a copy of this license, visit http://creativecommons.org/licenses/by/4.0/

(C) The Author(s) 2017

Supplementary Information accompanies this paper on Cell Death and Disease website (http://www.nature.com/cddis) 